\title{
Community-groundwater compatibility assessments: An approach towards sustainable groundwater development
}

\author{
JA Myburgh* and A Hugo \\ ${ }^{1}$ AGES Eastern Cape (Pty) Ltd, East London, South Africa
}

\begin{abstract}
To address water availability problems in a semi-arid country like South Africa, the National Water Act (RSA, 1998) proposes that specialists adopt an approach that is strategic, deliberate and dictated by socio-political reforms and socioeconomic development needs on a programmatic basis for long-term sustainability. To achieve this goal an approach is developed to determine community-groundwater compatibility as part of the initial stages of regional rural groundwaterdevelopment projects in the Eastern Cape Province, South Africa. The steps followed in the community-groundwater compatibility assessment include:

- A desktop study where available literature is collected and reviewed. From this information and history, the sociopolitical challenges that will have to be faced for the successful completion of the groundwater-development project in the study area can often be established. This is valuable information to assist the hydrogeological team in planning the community-groundwater compatibility assessment, taking note of pitfalls and lessons learnt from previous approaches that might not always have been successful.

- A socio-economic characterisation includes setting up a contact database for the community authorities and technical managers within the study. The contact database includes all contact details of the ward councillors/technical managers as well as any relevant information or comments made by the ward councillor/technical manager during the conversation. All identified stakeholders must also be contacted, informing them of the project and study. The data obtained from the role-players are used to develop a social-character map.

- Site surveys and sampling are based on the social-character map. The study team assesses the knowledge communities carry concerning groundwater as well as their general attitude towards the use of groundwater.

- Data processing and analyses include the statistical processing of the collected data to assess the comprehensive measure of groundwater compatibility per area, and the individual indicators of the groundwater-compatibility index are given a relative score. This enables the different indicators for groundwater compatibility per area to be combined to give a single composite score for each spatial area.
\end{abstract}

Target areas are finally characterised in terms of their 'community-groundwater compatibility index'. Maps showing the social and basic hydrogeological character of target areas are valuable tools towards assisting local authorities in decision-making.

Keywords: community-groundwater compatibility, groundwater sustainability, community awareness

\section{Introduction}

The main objective of a community-groundwater compatibility assessment is to proactively determine the communities' attitude towards and knowledge of local groundwater sources. These variables are of the essence towards planning and ensuring the sustainability of especially larger regional water-supply projects.

From a social perspective, the sustainability of a groundwater-supply project is largely determined by many powerful social, political, structural and economic factors. An understanding of these factors is critical, not only to develop sustainable groundwater-supply systems, but also to understand and implement appropriate future monitoring, management and intervention programmes.

This paper was originally presented at the International Conference on Groundwater: Our Source of Security in an Uncertain Future, Pretoria, 19-21 September 2011.

* To whom all correspondence should be addressed.

욜 +27 43 726-2070; fax: +27 43 726-9232;

e-mail: jmyburgh@ages-group.com
This paper emphasises the importance of the social aspect of the community-groundwater compatibility assessment and therefore the various facets of social assessment are discussed briefly.

Models of behavioural change that can be applied as basis for a community-groundwater compatibility assessment include:

- The Health Belief Model

- The Theory of Reasoned Action

- Social Learning Theory

These models are based on the assumption that water-conservation-related activities are determined by individual's knowledge and understanding. Behavioural change is a concept that has often been used in the field of health endorsement, and has taken on the metaphors from information technology such as referring to human cognition as 'information processing' (Campbell, 1997; Joffe, 1996; Kelly et al., 2001). Three prominent models of behavioural change are outlined below:

- The underlying assumption of the Health Belief Model is that if an individual perceives her/himself to be at risk, this will induce preventative behaviour. An individual's beliefs can also be influenced by socio-demographic features, for 


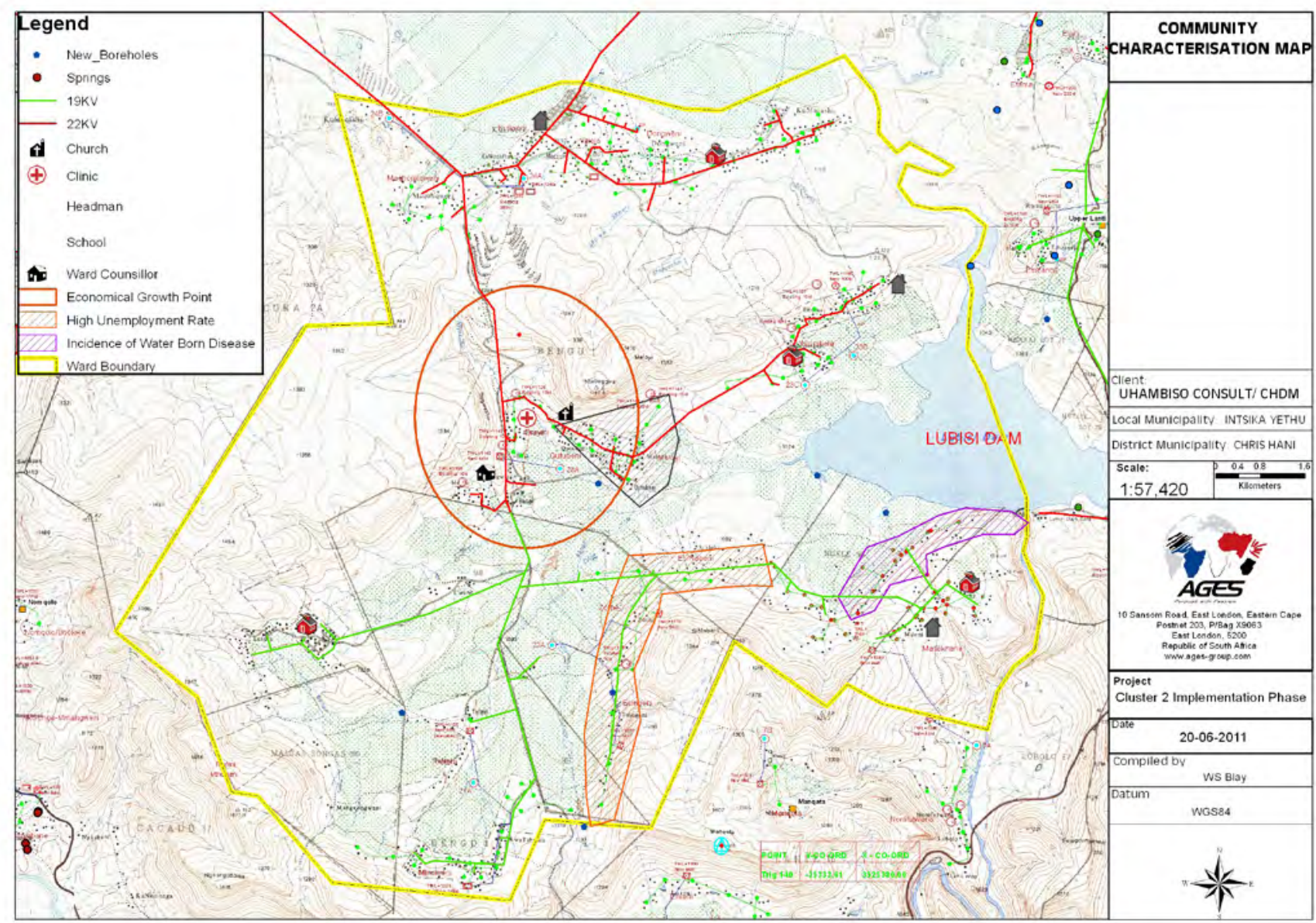

Figure 1

Social-character map

instance an individual's age, gender, awareness and culture, personality makeup, and other personal distinctions (Joffe, 1996; Kelly et al., 2001).

- The Theory of Reasoned Action was developed by Martin Fishbein and Icek Ajzen (Fishbein and Ajzen, 1975; Ajzen and Fishbein, 1980) and presupposes a connection between an individual's beliefs, attitudes and his/her consequent behaviour. Behaviour is the result of wanting to act in a certain way, which is influenced by how an individual thinks and feels about a certain action as well as how society views that action.

- The Social Learning Theory addresses the link between how individuals think and how individuals act in a particular situation. The Social Learning Theory is based on the presupposition that an individual's behaviour, environmental influences, and personal variables are decidedly interactive and reliant on each other (Sternberg, 1995).

Any water-conservation campaign developed using this theory would contain 4 main aspects (Kelly et al., 2001). The first angle would be to increase individuals' awareness of groundwater and their knowledge about it. The second approach would be to improve individuals' self-efficacy so that they believe that their behaviour would be successfully executed. The third component would aim to equip individuals with the necessary skills required to govern their own behaviour. The final element would aspire to generate social supports and strengthening for behavioural changes in communities. These elements form the foundation of the proposed methodology for the assessment of community-groundwater compatibility.

\section{Proposed methodology}

The proposed methodology can be broken down into the steps discussed below.

\section{Step 1: Desktop study}

To initiate a community-groundwater compatibility assessment that will support hydrogeological potential determination and groundwater-development studies, a preliminary review of the available literature is necessary. In South Africa, and specifically in regional rural water-supply projects, political changes and financial complexities have often resulted in delays, resulting in a database of information and reports of different phases and approaches being available to the reviewer. From this information and the associated history, the socio-political challenges can be determined and this can assist in the successful completion of the groundwaterdevelopment project in the study area. This includes not only the social fabric of the authorities involved but also the communities that are at stake. This is valuable information to assist the hydrogeological team in planning the communitygroundwater compatibility assessment, taking note of pitfalls and lessons learnt from previous approaches that might not always have been successful. 


\section{Step 2: Socio-economic characterisation}

Prior to commencing with field work and site surveys, the study team sets up a contact database for the community authorities and technical managers within the study area. The contact database established indicates information that reflects the contact details of all the ward councillors/technical managers, the date and time on which contact was made, the purpose of contact, as well as any relevant information or comments made by the ward councillor/technical manager during the conversation and the response given by the social facilitator.

Next, various identified stakeholders are contacted, informing them of the project. Their permission is requested to conduct the study in their areas of responsibility. The creation of a social-character map of the study area (Fig. 1), forms the basis from which further planning can commence. The socialcharacter map also assists surveyors to immediately 'see' the social character of the ward by identifying important information such as village demarcations; project steering committees and water committee demarcations; existing groundwater and sanitation infrastructure; social problems experienced in the areas; demarcation of schools, clinics, police stations and churches; other water users such as irrigation schemes; sources of food; and availability of electricity.

In order to make a project sustainable, it is important that key persons in the community are involved when developing these social-character maps as it already paves the way towards creating a sense of understanding and ownership in their area of responsibility. On the map, the community would, amongst various other things, indicate which areas they believed would be more suitable areas to host well-fields; identify villages most in need of water and prone to waterborne diseases; and where the project was most at risk of vandalism due to social problems.

The social-character map may also serve as a useful tool for consultants working in an area. The consultants can determine the social character of an area by identifying important information such as the contact details of key community leaders necessary to discuss important project-related information. In unstable areas the project may be prone to vandalism; these areas include high crime-rate zones or areas where social problems such as drug or alcohol abuse are rife. Once hand-drawn social-character maps are completed by the community members, they are converted into GIS format for planning applications (Myburgh and Hugo, 2010a).

\section{Step 3: Site surveys and sampling}

Using the social-character map as basis, it is further necessary to carry out site surveys to determine groundwater knowledge and compatibility levels across the study area. Purposive sampling is employed to recruit a representative number of participants from the population. The purpose of the survey is to identify social factors that may influence the sustainability of the larger water-supply project. The study team assesses community knowledge concerning groundwater as well as communities' general attitude towards the use of groundwater.

A number of ethical issues are raised by the approach; however, it is important to note that participation is voluntary; information is given about the project with no distortion of detail and identities are kept confidential. Care is taken to explain the purpose of the survey to participants in order to prevent unrealistic expectations. The groundwatercompatibility survey is usually conducted as part of a larger socio-economic survey executed by the larger study team. The socio-economic assessment creates an opportunity for the groundwater team to incorporate a subset of questions that would provide them with the data required for the communitygroundwater compatibility assessment. Surveyors are trained in the local dialect and each question is revised in order to minimise incorrect interpretation. The focus of the questionnaire survey is to determine the community member's:

- Knowledge about groundwater in general, conditions and occurrences

- Attitudes towards groundwater and perceptions regarding groundwater quality

- Understanding the link between groundwater and on-site sanitation and health-related issues

- Perceptions regarding the link between groundwater and springs

- Perceptions regarding groundwater infrastructure and safety

\section{Step 4: Data processing and analyses}

Once the relevant variables have been measured, the data are captured and entered into Excel worksheets. The scores on these variables are processed quantitatively in order to describe the data more succinctly. Labelled themes that characterise various sections of the data are identified. Theme titles are conceptually based on the essence of the data and structure is introduced into the analysis. The themes identified are listed and considered in relation to one another. Some of the themes form clusters of concepts that share similar notions. An example of summary charts of the structured themes is produced for each individual target area surveyed as indicated in Fig. 2. The summary charts consist of the cluster labels collectively with their subordinate theme labels.

\section{How does the community feel about having groundwater as a water} source?

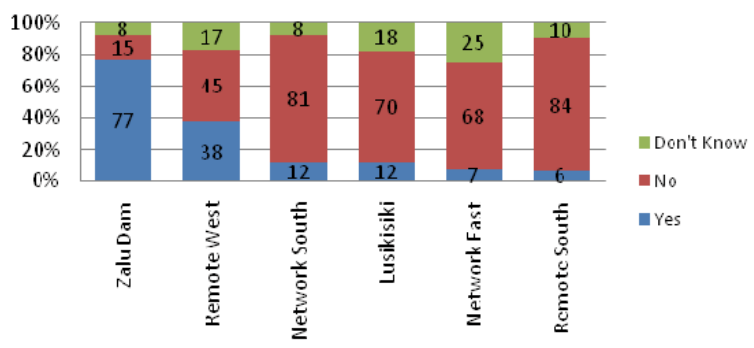



Figure 2

Processed compatibility-assessment data outputs 


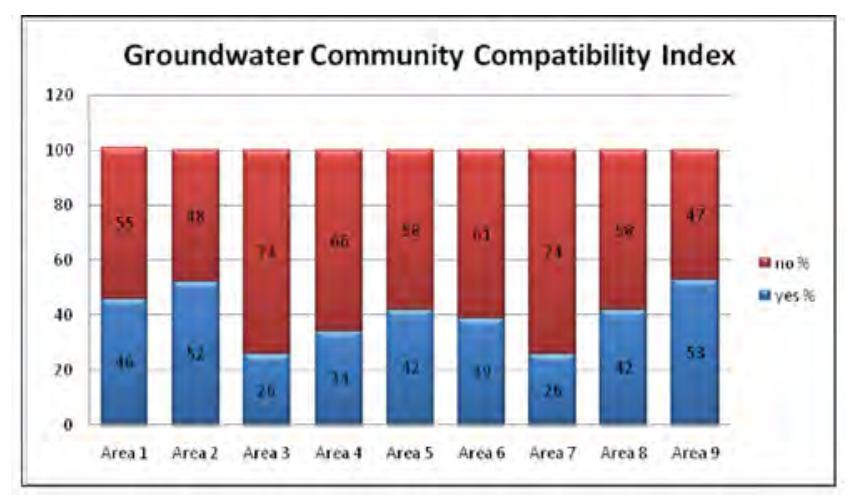

Figure 3

Compatibility index comparison

In order determine a comprehensive measure of groundwater compatibility per area, the individual indicators of the groundwater-compatibility index are given a relative score. This enables the different indicators for groundwater compatibility per area to be combined to give a single composite score for each spatial area (Myburgh et al., 2011).

\section{Step 5: Calculating the community-groundwater compatibility assessment and interpretation of results}

To calculate the final community-groundwater compatibility index, the applicable scores of all the identified target areas are combined into a composite score and statistically transformed into a percentage as indicated in Fig. 3. For example, 9 different groundwater well-field target areas need to be compared in terms of the groundwater compatibilities of communities in each target area. The combined results of the survey can then be used to compare different parts of the study area or identified target areas to list zones of higher and lower compatibility. The low compatibilities are indicative of areas where awareness levels need to be increased to support sustainable groundwater development. GIS outputs are valuable for the spatial distribution of different zones of variable compatibilities as indicated in Fig. 4 (Myburgh and Hugo, 2010b).

Figure 4 indicates the average percentage of communitygroundwater compatibility per area and in this specific example, the difference in compatibility between areas could be used to decide which areas should have preference for regional groundwater-source development from a community involvement and awareness perspective. The map also indicates areas that require community-groundwater awareness programmes prior to implementation phases. In extreme cases, areas with low compatibility indexes have been found to be prone to vandalism of groundwater-abstraction infrastructure. Negativity can also be experienced towards groundwater monitoring and management initiatives. These areas are also more prone to groundwater pollution from, for example, poor sanitation practices due to low levels of groundwater awareness.

Social survey data can also be used to determine preferences between different water sources. This approach is based on the outcome of data indicating source preference based on the community's knowledge and perceptions/expectations of

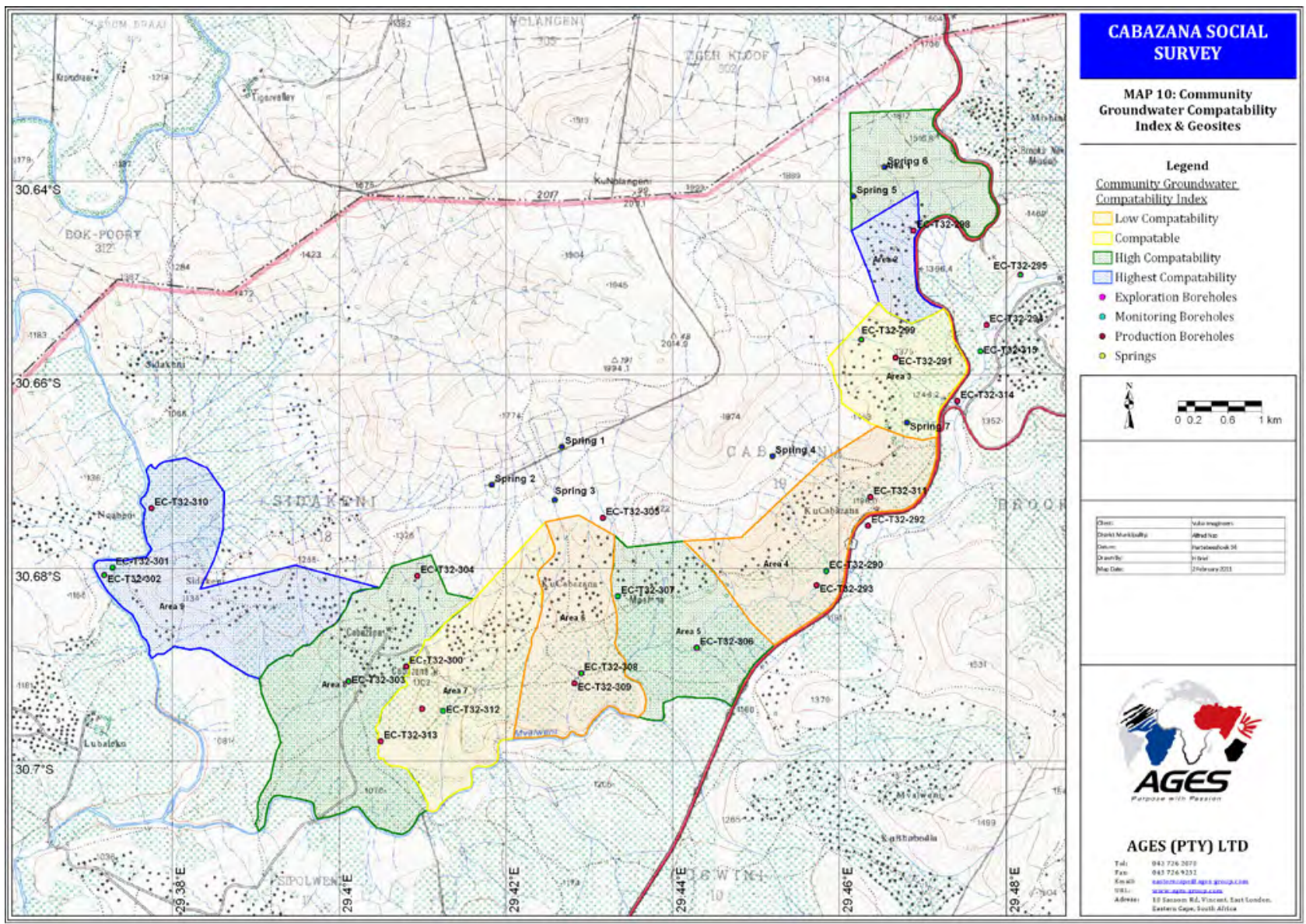

Figure 4

Regional compatibility index comparison 




Figure 5

Regional source preference comparison

the various sources. Sub-themes define perceptions and preferences regarding water quantity, quality, the cost to develop and maintain each source, the sustainability of each source, and the communities' preferred water source based on their experience and expectations. Figure 5 gives an example of the outcome of such an assessment where a regional water-supply scheme needed to be assessed in terms of finding the balance between water supply from a combined surface water-groundwater source and to identify zones where awareness-creation programmes need to be launched. For instance, should a surfacewater source be developed in an area where communities prefer groundwater or springs as source or vice versa? Three water sources were compared in this specific project, namely, groundwater, spring water and surface water.

\section{Applications of methodology when conducting groundwater assessments}

Primarily, regional groundwater-supply assessments need to be approached from a hydrogeological perspective. From experience it has been found that this approach cannot be followed in isolation and that the other main components of such a regional assessment need to be incorporated when evaluating the most feasible development options. The 3 main components that need to form part of regional groundwater assessments for bulk water supply can be defined as:

- Groundwater-community compatibility assessment

- Groundwater potential and Reserve determination

- Engineering design optimisation

\section{Groundwater potential and Reserve determination}

Regional groundwater-supply assessments always need to be approached from the perspective of determining the groundwater Reserve. This is usually applied to delineated groundwater-management units. Outcomes can then be defined in terms of volumes of allocatable groundwater, stress indexes for the different groundwater units and delineation of higher groundwater-potential zones. Figure 6 gives an example of the outcome of a desktop exercise in groundwater Reserve determination, applied to the same regional groundwater-supply project referenced in Fig. 5, which indicates where groundwatercompatibility assessments were carried out in different target areas. Hydrogeological principles defining groundwater potential are obviously the most determining factors when assessing regional groundwater-supply -options but should not be seen in isolation when prioritising development zones. Community preferences and perceptions that are not in line with the final development framework can have negative impacts on regional water-supply schemes in terms of long-term sustainability and therefore it is advised that the community-groundwater compatibility assessment is carried out before work commences on developing groundwater-supply schemes.

Zones of higher volumes of allocatable groundwater available towards the east and north of the study area, shown in Fig. 6, have contributed to the final decision that regional well-field development should be considered and prioritised in these areas. The outcome of the groundwater-community 


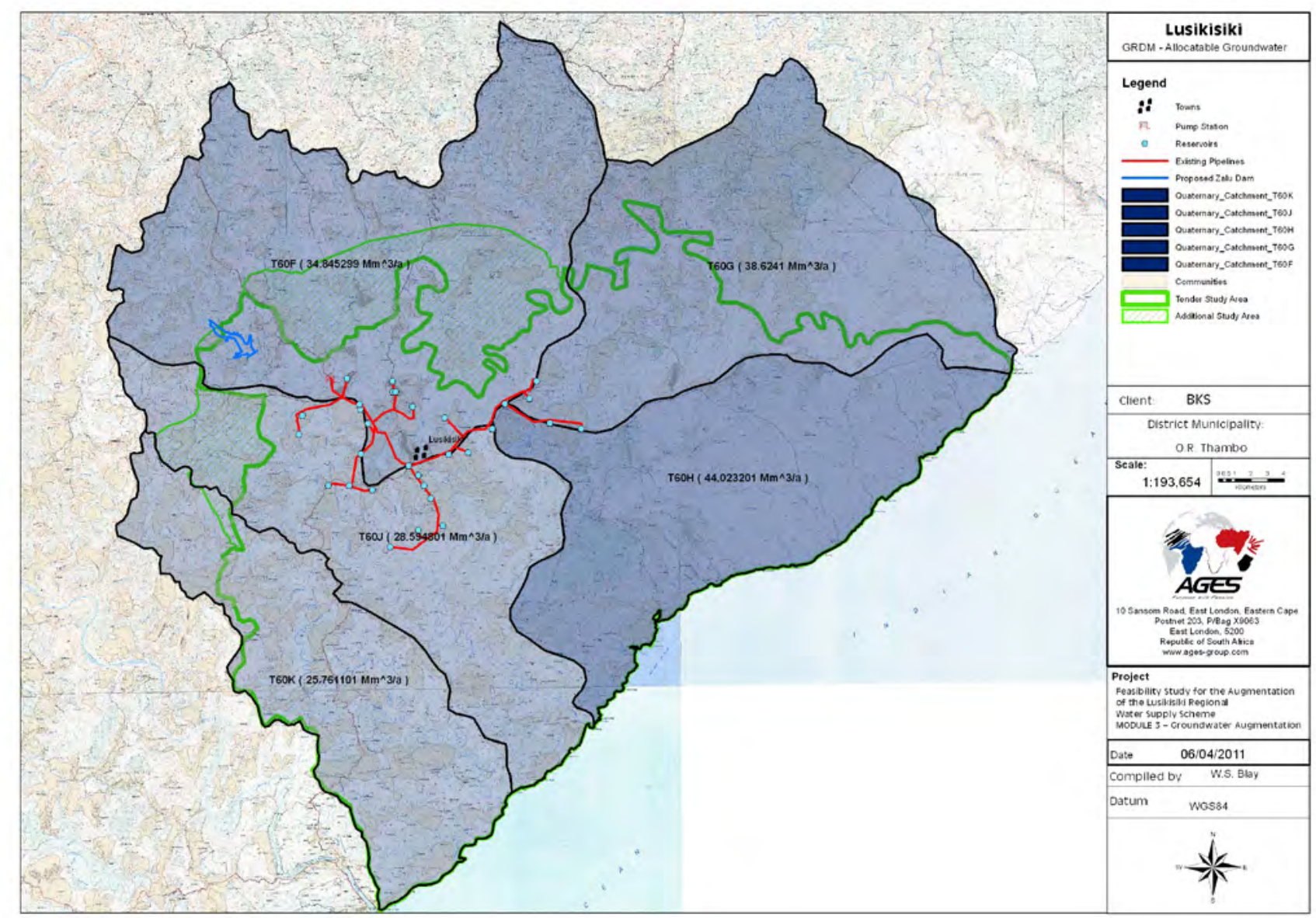

Figure 6

Groundwater Reserve determination - regional comparisons

compatibility assessment has, however, indicated low groundwater awareness and attitude levels in these same areas. This observation has resulted in the development of a programme to increase groundwater awareness for implementation in the high-potential groundwater areas to ensure community buy-in and long-term sustainability (Myburgh et al., 2011)

\section{Engineering design optimisation}

Regional groundwater-development projects that have a scope and extent beyond local single village water supply need to be approached with cognizance of long-term sustainability factors. These factors include delineation of regional groundwater potential zones, operation and maintenance costs as well as community-groundwater compatibility profiles. Based on such an integrated approach, the optimum final water-supply infrastructure design can be established and implemented. Regional groundwater-development projects often result in bulk-water approaches being followed where the groundwater source is developed in the same manner as a surface-water source. This is possible if well-fields, developed from target areas of high groundwater potential and high-yielding boreholes, can be clustered in manageable units which can serve numerous communities. Finding the optimum balance between how many to develop and identifying potential target areas for well-field placement, necessitates the investigator to compare topographical settings and head-elevation differences between well-field areas as well as comparing capital and operating expenditures based on the optimum number of well-fields that will serve the entire project. Should groundwater and surface water both be an option for regional water supply, it will be crucial to evaluate and compare the differences in capital and operating expenditure for each scenario. Figures 7 and 8 give an indication of these conceptual assessments where different scenarios are compared, ranging from sole groundwater-source development options to combinations of groundwater and surface sources.

By comparing 3 different scenarios applicable to the specific project referred to in the figures above, the outcome based on capital and operating expenditures over the lifetime of the project clearly indicates in Fig. 9 that groundwater is by far the more cost-effective source to be developed.

\section{Groundwater-awareness creation and training}

Groundwater-awareness programmes that support and enhance the project's institutional and social development approach can be developed based on the findings of site surveys and outcomes of compatibility assessment, as well as having assessments of integrated groundwater potential, Reserve determination studies, and engineering-design optimisation. The purpose of the awareness programmes is to increase project sustainability through creating awareness around groundwater and stimulate sensitivity within participants concerning the importance of this source where and if applicable. The main suppositions are based on the assumption that community 


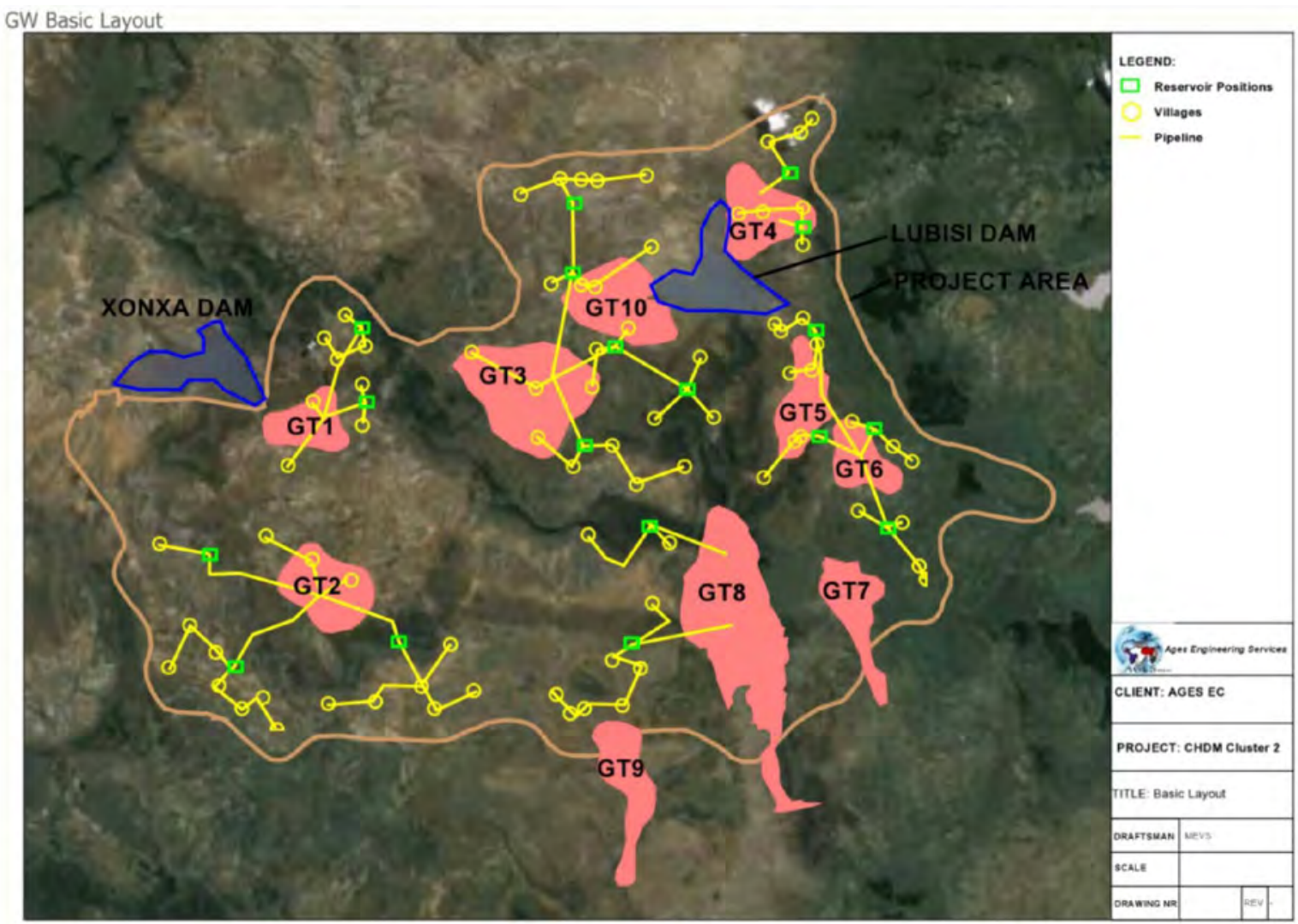

Figure 7

Conceptual designs for groundwater-source development

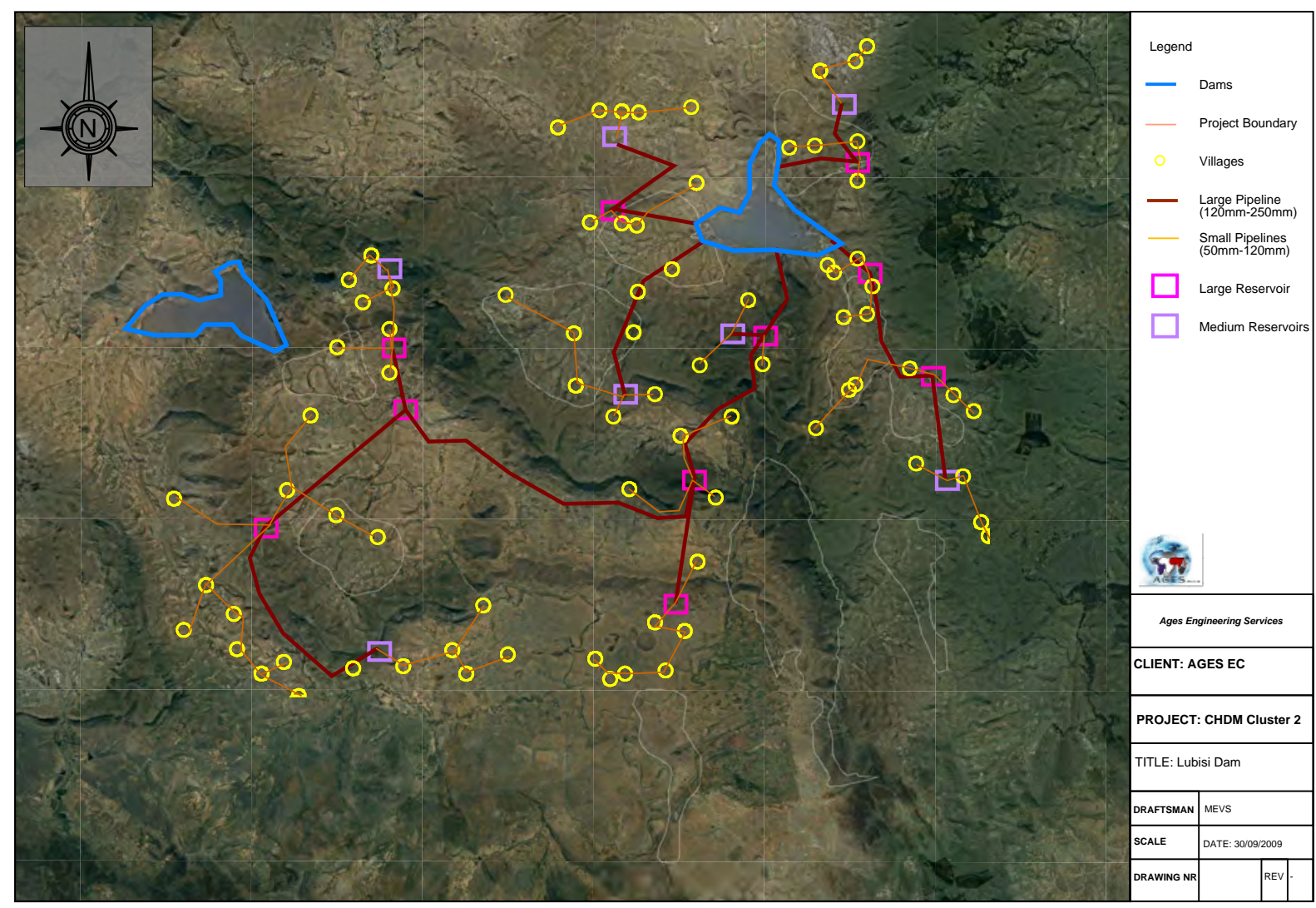

Figure 8

Conceptual designs for development of surface-water sources 


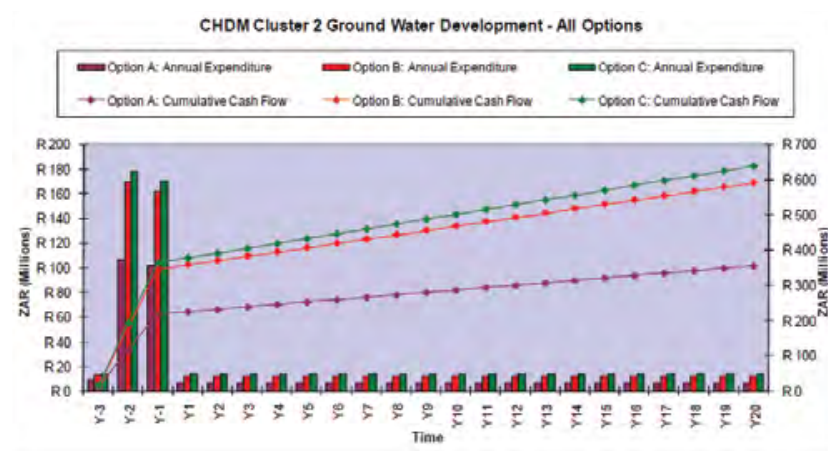

Figure 9

Comparison of capital and operating expenditure between different scenarios

members will understand the information thoroughly and will be sufficiently motivated to act on this information to manage and protect their groundwater, if they are presented with the following information:

- Appropriate information regarding the characteristics of groundwater

- Come to the understanding that groundwater is a restricted resource and can be impacted if not managed properly

- Discover how groundwater can be polluted.

The premise is that it would lead to long-term project sustainability. Figure 10 gives an example of the outcome of a specific community-groundwater compatibility assessment which has resulted in the identification of areas where attitudes regarding groundwater have been found to be more negative and therefore areas where groundwater-awareness creation needs to be increased prior to the implementation of further groundwater development (Myburgh et al., 2011).

In order to ensure that all of these premises are met, the intervention is meticulously planned using well practised sociological principles to develop and implement an intervention plan. One method to provide large numbers of individuals with information in an easy and understandable manner and create motivation involves presenting groundwater-awareness workshops. Workshops are one of the most effective methods to promote change in individuals. Individuals do much of their learning by interacting with, observing and listening to peers. In order to facilitate change in individuals and maximise the potential, a clear understanding must exist of the theoretical approach that will guide the workshop. For instance, community members may have previously formed perceptions relating to groundwater in accordance to the views and opinions historically expressed and taught by their local communities. These perceptions may lack some of the more scientific explanations of how groundwater accumulates, becomes polluted and depleted. For example, it has been observed that some rural communities perceive groundwater as coming from salt underground that dissolves and turns into water. In view of the fact that the social team's main purpose for conducting the workshop is to create an awareness around groundwater, it becomes vital for new information to be introduced to those attending the workshop to revise and replace any insufficient constructs around groundwater.

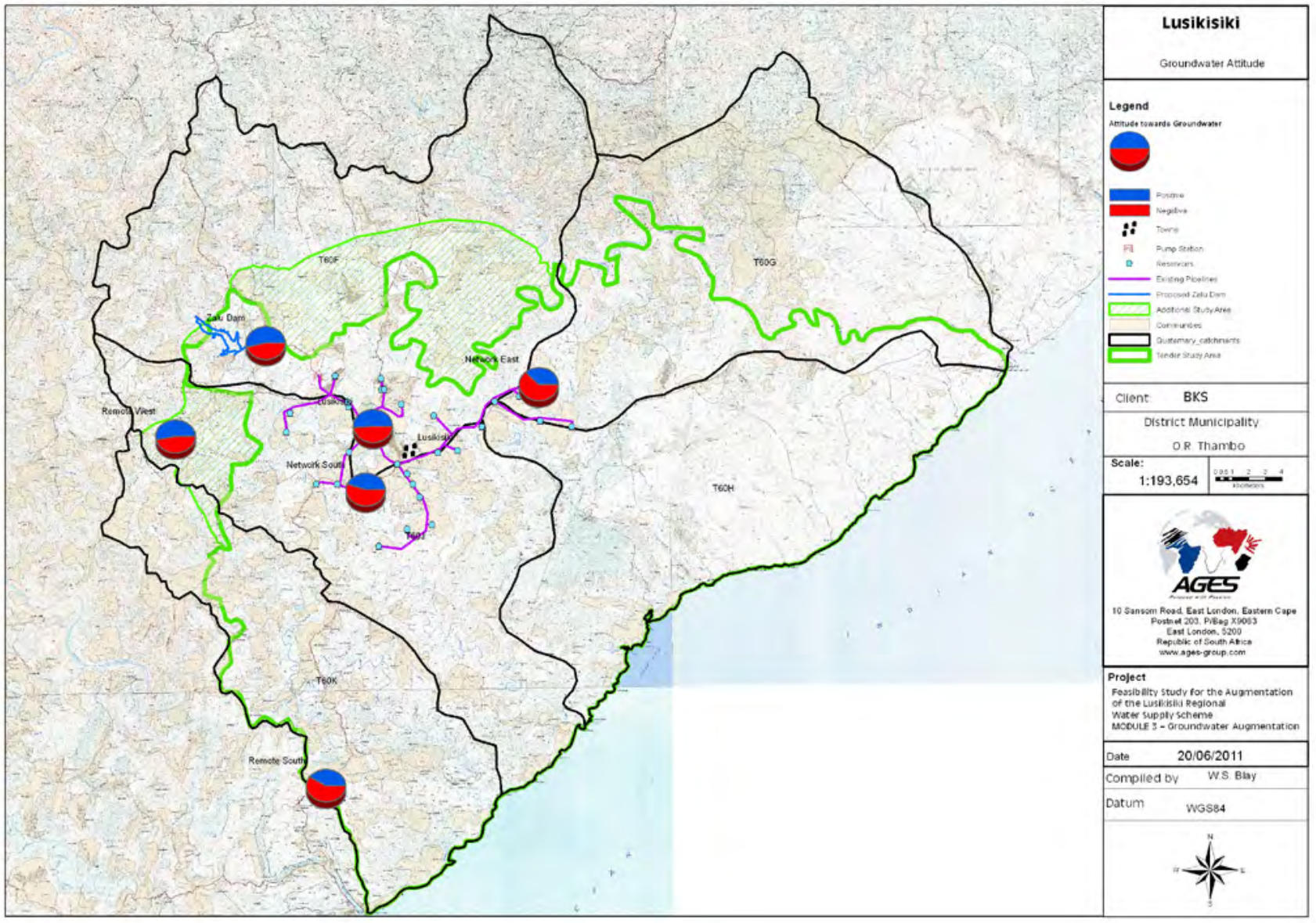

Figure 10

Comparative regional community-groundwater attitude analyses 


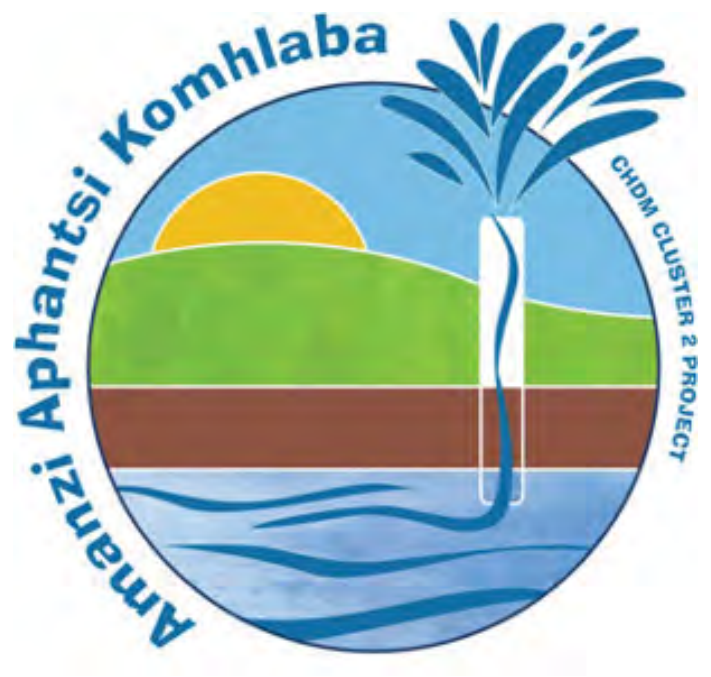

Figure 11

Project-specific logo development

The nature of the groundwater-awareness workshop is psycho-educational. It aims at changing behavioural responses by exploring values and beliefs and teaching new ways of thinking and behaving. Psycho-educational workshops provide an opportunity for helping individuals to learn and develop healthy constructs, and consequently to change their attitudes and behaviour in order to cure the prejudice and prevent the continuation and/or development of unnecessary problems. Although the focus is on learning, the process usually involves group interaction with members of the group sharing and discussing thoughts, feelings, experiences, attitudes, beliefs and values, particularly as these relate to relevant topics.

Activities are very important tools for working with groups. Activities promote a sense of competence and a sense of belonging. Activities also provide the opportunity for self-growth and learning. When designing the workshop, the programme is varied in the use of method and activity while maintaining a focus likely to result in the achievement of the goals. Workshop participants receive material to recap the presentation and to explain any questions that may have arisen. The material is visual and informative to allow people who cannot read to follow the material. They are provided with informative material to leave with fellow community members. Thus they are further equipped to answer the questions that may arise in the community. The social team and field workers also extensively distribute groundwater psycho-educational information in the form of posters, pamphlets, stickers and project-branded water containers across the entire project area. The material used is easy to understand by all members of the community and it is culturally sensitive. All material is visual with pictures and illustrations and is presented in the local language. An example of such a project-specific logo is given in Fig. 11; this helps the community to understand and take pride in the fact that their community will be relying on an underground water source. Such logos are attached to water containers and distributed to schools and community members during awareness programmes.

Research studies relating to the outcomes of workshops suggest that individuals can derive considerable psycho-educational benefit and demonstrate improved psychosocial functioning as a result of attending the workshop. However, this does not mean that all workshops will necessarily be able to achieve their defined objectives. In order to be accountable, therefore, it is desirable to take specific action to evaluate the outcome of the workshop. Continuous assessment techniques are employed to evaluate the groundwater-awareness workshop presented (Myburgh and Hugo, 2010a).

\section{Conclusions}

This paper demonstrates how applied research can be implemented in groundwater assessments. An approach is developed to determine community-groundwater compatibility as part of the initial stages of regional rural groundwater-development projects in the Eastern Cape Province, South Africa. This approach is designed to ensure that the development of groundwater resources, in an environment where communities live in close proximity and relation to their groundwater sources, be planned and approached with cognizance of the factors that determine the compatibility between the water source and the end user.

The results of community-groundwater compatibility assessment can be used to:

- Identify areas where awareness levels need to be increased to support sustainable groundwater development

- Identify areas where negativity could be experienced towards groundwater-monitoring and -management initiatives. These areas are also more prone to groundwater pollution from, for example, poor sanitation practices due to low levels of groundwater awareness.

- Find the acceptable balance for the community between water sources, for example groundwater, spring water and surface water

- Develop groundwater-awareness programmes in groundwater areas with high potential to ensure community buy-in and long-term sustainability.

Increased groundwater awareness will lead to the community:

- Having the correct information regarding the characteristics of groundwater

- Coming to the understanding that groundwater is a restricted resource and can be impacted if not managed properly

- Discovering how groundwater can be polluted

- Understanding information thoroughly

- Being sufficiently motivated to act on this information to manage and protect their groundwater sources.

It is important to note that this methodology is data dependent. In addition, social and water sciences are based on quantitative methods to understand and assess situations. Based on the amount and quality of data available it is recommended that an indication of the level of confidence of the assessment and associated results be given to the end-user to ensure that it is applied effectively and at the appropriate confidence level of the study or project in question.

It is recommended that the proposed methodology be implemented and evaluated in terms of the results of targeted awareness programmes. The results of this evaluation should be used to improve the current methodology. In addition, the current methodology can be expanded to include groundwater quality and the optimisation of mitigation options.

\section{References}

AJZEN I AND FISHBEIN M (1980) Understanding Attitudes and Predicting Social Behavior. Prentice-Hall, Englewood Cliffs, NJ. 
CAMPBELL C (1997) Migration, masculine identities and AIDS: The psychosocial context of HIV transmission on the South African gold mines. Soc. Psychol. Med. 45 (2) 273-281.

FISHBEIN M AND AJZEN I (1975) Belief, Attitude, Intention, and Behavior: An introduction to Theory and Research. AddisonWesley, Reading, MA.

JOFFE H (1996) AIDS research and prevention: a social representational approach. Br. J. Med. Psychol. 69 169-190.

KELLY K, PARKER W and LEWIS G (2001) Reconceptualizing Behaviour Change in the HIV/AIDS Context. Socio-Political and Psychological Perspectives on South Africa. Nova Science, New York. 251-275.

MYBURGH JA and HUGO A (2010a) Cluster 2 Implementation - Community Liaison, Awareness Creation \& Groundwater Compatibility Assessment. Chris Hani District Municipality,
Eastern Cape. Report 2010/06/06/GWSD-A. AGES Eastern Cape, East London.

MYBURGH JA and HUGO A (2010b) Cabazana Groundwater Source Development: Alfred Nzo District Municipality - Community Liaison, Awareness Creation and Groundwater Compatibility Assessment. Report No. 2010/11/09/GWSD. AGES Eastern Cape, East London.

MYBURGH JA, HUGO A and BLAY W (2011) Feasibility Study for the Augmentation of the Lusikisiki Regional Water Supply Scheme MODULE 3 - Groundwater Augmentation. Report No. 2011/03/14/ SCL. AGES Eastern Cape, East London, South Africa.

RSA (REPUBLIC OF SOUTH AFRICA) (1998) National Water Act, Act No 36 of 1998. Government Gazette No. 19182. RSA, Cape Town, South Africa.

STERNBERG RJ (1995) In Search of the Human Mind. Harcourt Brace College, Orlando, Florida, USA. 